\section{Hyponatremia can be a powerful predictor of the development of isolated ACTH deficiency associated with nivolumab treatment}

\section{Dear Editor,}

The report of nivolumab-induced hypophysitis by Okano et al. was of great interest to us [1]. We have experienced four cases of isolated ACTH deficiency after nivolumab administration, suggesting that decreased sodium $(\mathrm{Na})$ concentrations during nivolumab therapy may predict the acute development of isolated ACTH deficiency.

The underlying diseases in these four patients were malignant melanoma (case 1) [2] or non-small cell lung carcinoma (cases 2-4) >stage 4 (Table 1). Nivolumab $(2 \mathrm{mg} / \mathrm{kg}$, every 3 weeks) was effective for treating the cancer in three patients (cases 1-3), while case 4 was considered to have progressive disease and the treatment was discontinued after the 6th administration. All patients experienced fatigue, appetite loss, nausea, and body pain from the 6th to 10th nivolumab administrations. All four patients had low blood pressure and hyponatremia with markedly low ACTH and cortisol levels on admission. Neither ACTH nor cortisol

Kyu Yong $\mathrm{Cho}^{1)}$, Hideaki Miyoshi $^{1)}$, Akinobu Nakamura ${ }^{1)}$, Takashi Kurita $^{2)}$ and Tatsuya Atsumi ${ }^{1)}$

1) Division of Rheumatology, Endocrinology and Nephrology, Hokkaido University Graduate School of Medicine, Sapporo 060-8638, Japan

2) Department of Internal Medicine, Japanese Red Cross Kitami Hospital, Kitami 090-8666, Japan

Submitted Dec. 11, 2016; Accepted Dec. 19, 2016 as EJ16-0596

Released online in J-STAGE as advance publication Jan. 6, 2017

Correspondence to: Kyu Yong Cho, Division of Rheumatology, Endocrinology and Nephrology, Hokkaido University Graduate School of Medicine, North 15, West 7, Kita-ku, Sapporo, Hokkaido 060-8638, Japan. E-mail: kyuyong-cho@med.hokudai.ac.jp responded to $\mathrm{CRH}$ stimulation tests, and the cortisol reaction to the conventional-dose short ACTH stimulation test $(250 \mu \mathrm{g})$ was lower than normal. Cortisol was secreted following prolonged-stimulation tests in cases 1 and 2 (not determined in cases 3 and 4). The secretion of other pituitary hormones was normal. Magnetic resonance imaging showed no abnormalities. Based on these findings, the patients were diagnosed with isolated ACTH deficiency induced by nivolumab treatment. Their symptoms resolved and general conditions improved promptly after initiation of hydrocortisone $(15-20 \mathrm{mg} /$ day). There was no appearance of polyuria after hydrocortisone replacement.

Symptoms such as fatigue developed within 6 days after the last nivolumab treatment, and hydrocortisone was initiated from 7-14 days after treatment in three of the four patients. None of the apparent clinical symptoms that would indicate adrenal insufficiency had been observed at the last administration of nivolumab. However, we noted hyponatremia (serum $\mathrm{Na}$ levels $<135 \mathrm{mEq} / \mathrm{L}$ ) in two patients (cases 1 and 2) [3] in the absence of such symptoms. In addition, serum $\mathrm{Na}$ levels in three patients (cases 1-3) were clearly reduced by the time of the last administration. Hyponatremia could thus be the first manifestation indicating ACTH deficiency in patients treated with nivolumab, followed by other symptoms or physical findings. A previous report by Asano et al. showed that hyponatremia was frequently detected in elderly patients with hypopituitarism, most of whom had ACTH deficiency, and the mechanism of hyponatremia in these patients may have involved augmented release of arginine vasopressin due to impaired pituitary-adrenal axis function [4]. A similar mechanism may have been responsible for the nivolumab-induced hyponatremia in ACTH deficiency in the patients (54-76 years old) in our study.

Adrenocortical failure caused by isolated ACTH deficiency may be life-threatening, especially in frail patients with cancer. Our cases highlight the importance of comparing serum $\mathrm{Na}$ levels before and during treatment, and measuring $\mathrm{ACTH}$ and cortisol levels in patients with hyponatremia during nivolumab treatment. 
Table 1 Clinical features and treatment in four cancer patients who developed nivolumab-associated isolated ACTH deficiency

\begin{tabular}{|c|c|c|c|c|}
\hline Case & 1 & 2 & 3 & 4 \\
\hline Age (y.o.) & 76 & 54 & 64 & 57 \\
\hline Sex & Female & Male & Male & Male \\
\hline Disease & $\begin{array}{l}\text { Malignant } \\
\text { melanoma }\end{array}$ & $\begin{array}{l}\text { Poorly differentiated } \\
\text { lung carcinoma }\end{array}$ & $\begin{array}{l}\text { Lung } \\
\text { adenocarcinoma }\end{array}$ & $\begin{array}{l}\text { Large cell lung } \\
\text { carcinoma }\end{array}$ \\
\hline Nivolumab administration (times) & 9 & 8 & 7 & 6 \\
\hline Symptoms & $\begin{array}{l}\text { Fatigue } \\
\text { Appetite loss }\end{array}$ & $\begin{array}{l}\text { Fatigue } \\
\text { Nausea }\end{array}$ & $\begin{array}{l}\text { Fatigue } \\
\text { Appetite loss }\end{array}$ & $\begin{array}{l}\text { Appetite loss } \\
\text { Nausea } \\
\text { Body pain }\end{array}$ \\
\hline \multicolumn{5}{|l|}{ Period from last administration to (days) } \\
\hline Onset of symptoms & 4 & 4 & 6 & 26 \\
\hline Hydrocortisone initiation & 7 & 8 & 14 & 40 \\
\hline \multicolumn{5}{|l|}{ On admission } \\
\hline $\mathrm{ACTH}(\mathrm{pg} / \mathrm{mL})$ & 6.7 & 7.0 & $<2.0$ & 2.9 \\
\hline Cortisol $(\mu \mathrm{g} / \mathrm{dL})$ & $<1.0$ & $<1.0$ & $<1.0$ & $<1.0$ \\
\hline Effect on hydrocortisone & Effective & Effective & Effective & Effective \\
\hline \multicolumn{5}{|l|}{ Symptoms } \\
\hline 3 weeks before from last administration & $(-)$ & $(-)$ & $(-)$ & $(-)$ \\
\hline Last administration & $(-)$ & $(-)$ & $(-)$ & $(-)$ \\
\hline On admission & $(+)$ & $(+)$ & $(+)$ & $(+)$ \\
\hline \multicolumn{5}{|l|}{ Blood pressure (mmHg) } \\
\hline 3 weeks before from last administration & $122 / 55$ & $133 / 84$ & $135 / 72$ & $108 / 64$ \\
\hline Last administration & $122 / 67$ & $143 / 89$ & $130 / 82$ & $103 / 73$ \\
\hline On admission & $102 / 63$ & $117 / 79$ & $142 / 90$ & $92 / 57$ \\
\hline \multicolumn{5}{|l|}{ Plasma glucose (mg/dL) } \\
\hline 3 weeks before from last administration & 129 & 95 & 96 & 96 \\
\hline Last administration & 104 & 99 & 85 & 151 \\
\hline On admission & 83 & 85 & 72 & 81 \\
\hline \multicolumn{5}{|l|}{ Serum sodium $(\mathrm{mEq} / \mathrm{L})$} \\
\hline 3 weeks before from last administration & 141 & 143 & 141 & 138 \\
\hline Last administration & $131 *$ & $134^{*}$ & 137 & 137 \\
\hline On admission & $123 *$ & $130 *$ & $127^{*}$ & 137 \\
\hline
\end{tabular}

y.o., years old; (-), no symptoms; (+), symptoms present. ${ }^{*}$ Hyponatremia (serum Na levels $<135 \mathrm{mEq} / \mathrm{L}$ ).

\section{References}

1. Okano Y, Satoh T, Horiguchi K, Toyoda M, Osaki A, et al. (2016) Nivolumab-induced hypophysitis in a patient with advanced malignant melanoma. Endocr $J$ 63: 905-912.

2. Narahira A, Yanagi T, Cho KY, Nakamura A, Miyoshi $\mathrm{H}$, et al. (2016) Isolated adrenocorticotropic hormone deficiency associated with nivolumab therapy. $J$
Dermatol doi: 10.1111/1346-8138.13571.

3. Mocan M, Terheş LM, Blaga SN (2016) Difficulties in the diagnosis and management of hyponatremia. Clujul Med 89: 464-469.

4. Asano T, Aoki A, Sasaki M, Ikoma A, Kakei M, et al. (2012) Hyponatremia is the valuable manifestation for initiating diagnosis of hypopituitarism in elderly. Endocr J 59: 1015-1020. 